\title{
Loneliness, Social Isolation, and Cardiovascular Health
}

\author{
Ning $\mathrm{Xia}^{1}$ and Huige $\mathrm{Li}^{1-3}$
}

\begin{abstract}
Significance: Social and demographic changes have led to an increased prevalence of loneliness and social isolation in modern society.

Recent Advances: Population-based studies have demonstrated that both objective social isolation and the perception of social isolation (loneliness) are correlated with a higher risk of mortality and that both are clearly risk factors for cardiovascular disease (CVD). Lonely individuals have increased peripheral vascular resistance and elevated blood pressure. Socially isolated animals develop more atherosclerosis than those housed in groups.

Critical Issues: Molecular mechanisms responsible for the increased cardiovascular risk are poorly understood. In recent reports, loneliness and social stress were associated with activation of the hypothalamic-pituitaryadrenocortical axis and the sympathetic nervous system. Repeated and chronic social stress leads to glucocorticoid resistance, enhanced myelopoiesis, upregulated proinflammatory gene expression, and oxidative stress. However, the causal role of these mechanisms in the development of loneliness-associated CVD remains unclear. Future Directions: Elucidation of the molecular mechanisms of how CVD is induced by loneliness and social isolation requires additional studies. Understanding of the pathomechanisms is essential for the development of therapeutic strategies to prevent the detrimental effects of social stress on health. Antioxid. Redox Signal. 28, $837-851$.
\end{abstract}

Keywords: loneliness, social isolation, cardiovascular disease, oxidative stress

\section{Introduction}

$\mathbf{L}$ ONELINESS, DEFINED AS THE discrepancy between a person's desired and actual social relationships, is an emotional response to social isolation, while social isolation is an objective measure of the lack of social connections or interactions. Consequently, loneliness is thought to be more related to relationship quality than quantity $(57,78)$.

In addition to physical presence, humans need relationships that provide mutual value and trust, and promote communication and collaboration toward common goals $(15,57,78)$. Although it is commonly thought that social isolation leads to loneliness, loneliness can be experienced within a marriage, family, friendship, or larger social group. In contrast, one can feel socially contented while being alone $(11,12,57,78)$.
The perception of social isolation is not restricted to humans; behaviors related to social isolation have been also documented in animals $(12,14)$. Perceived social isolation (PSI) has damaging effects on the physical health of humans and animals manifested by activation of the hypothalamic-pituitaryadrenal (HPA) axis and increased depressive behavior (14). Experiments with animals housed individually are important for investigating the molecular mechanisms and the causal effects of social deprivation in disease development $(11,119)$.

Social isolation and loneliness are common sources of chronic stress in adults $(82,124)$. Moreover, a growing number of individuals are at risk for loneliness in modern society because of social and demographic changes (78). People are living longer and the number of people aged 60 years and older has tripled since 1950. Older age is associated

\footnotetext{
${ }^{1}$ Department of Pharmacology, Johannes Gutenberg University Medical Center, Mainz, Germany.

${ }^{2}$ Center for Translational Vascular Biology (CTVB), Johannes Gutenberg University Medical Center, Mainz, Germany.

${ }^{3}$ German Center for Cardiovascular Research (DZHK), Partner Site Rhine-Main, Mainz, Germany.
}

(C) Ning Xia and Huige Li 2018; Published by Mary Ann Liebert, Inc. This Open Access article is distributed under the terms of the Creative Commons Attribution Noncommercial License (http://creativecommons.org/licenses/by-nc/4.0) which permits any noncommercial use, distribution, and reproduction in any medium, provided the original author(s) and the source are cited. 
with reduced social interactions, longer periods of time living alone, and higher prevalence of loneliness (49, 104). However, loneliness is more than simply the result of age-related losses but can be experienced at all stages of life $(7,74)$.

The prevalence of loneliness has increased commensurate with deferred marriage, increased two-income households, and increased residence in single-family homes (78). In addition, the Internet has completely changed the way people live and interact (15). Despite increased digital connectivity, more people are experiencing social isolation (15). Rather than enhancing well-being, recent studies suggest that social media may undermine it (68). The prevalence in modern society (Fig. 1) is high enough to justify intervention (92).

\section{Loneliness as a Mortality Risk Factor}

Chronic social isolation has been shown to increase the risks of morbidity and mortality similar to known factors, including high blood pressure, smoking, and obesity (60). A meta-analysis involving 148 studies and 308,849 individuals followed for an average of 7.5 years showed that this effect of social isolation was independent of other risk factors (Fig. 2). The quantity and quality of relationships have been inversely correlated with health risks $(58,59)$. Strong social relationships can increase the likelihood of survival by as much as $50 \%$ relative to individuals whose relationships are weaker (59). An increase in mortality has been correlated with both loneliness and social isolation $(58,125)$. The overall odds of mortality due to loneliness and social isolation are 1.50 , which was comparable to light smoking and greater than the risks due to obesity and hypertension (59). A recent metaanalysis indicated that social isolation, loneliness, and living alone increased the possibility of death by $\sim 29 \%, 26 \%$, and $32 \%$, respectively (58).

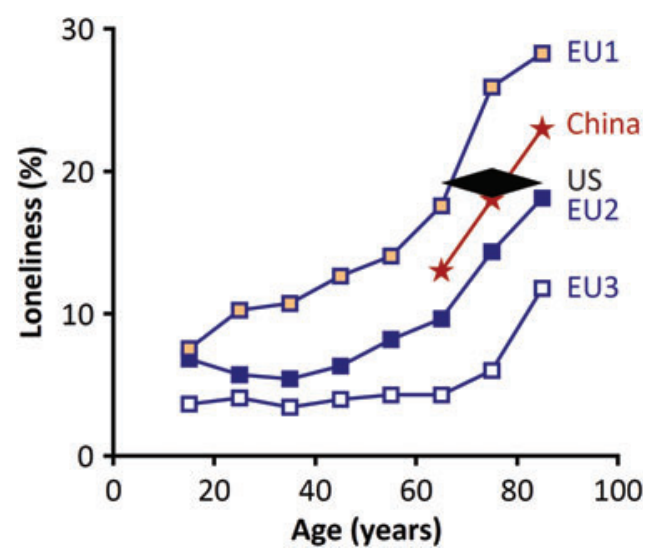

FIG. 1. Prevalence of loneliness. The reported prevalence of loneliness in Europe (148) and China (149), respectively. The overall prevalence of loneliness among adults older than 65 in the United States (135) is shown for comparison. There are significant differences in the prevalence among European countries with a higher prevalence in group EU1 (Bulgaria, Hungary, Latvia, Poland, Romania, Russia, Slovakia, and Ukraine) than group EU2 (Austria, Cyprus, Estonia, France, Portugal, Slovenia, and Spain), and group EU3 (Belgium, Denmark, Finland, Germany, Ireland, the Netherlands, Norway, Sweden, Switzerland, and the United Kingdom) (148). To see this illustration in color, the reader is referred to the web version of this article at www .liebertpub.com/ars

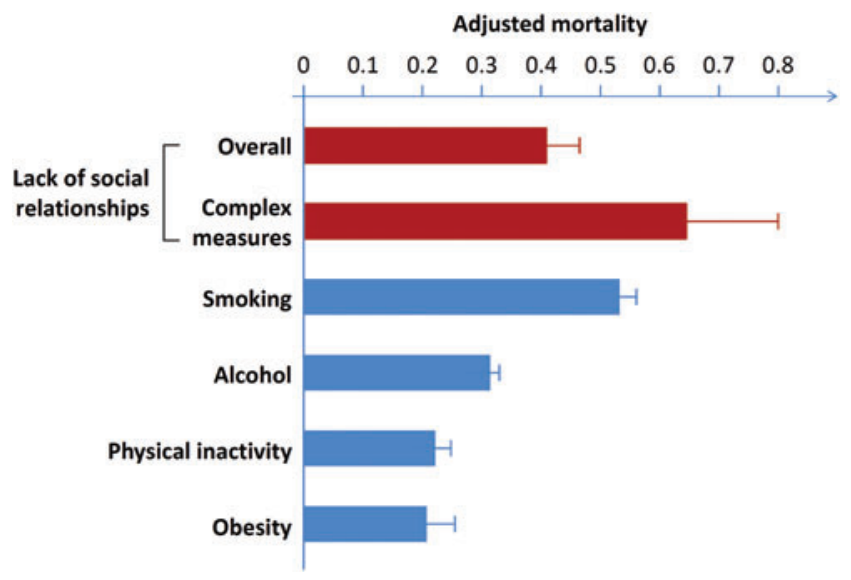

FIG. 2. Impact of social support on mortality. The odds of mortality due to social isolation and loneliness are similar to light smoking (15 cigarettes/day) and alcohol consumption (6 drinks/day), and exceed the risks conferred by physical inactivity and obesity. Note: Effect size of zero indicates no effect. Complex measures of social integration are single measures that assess multiple components of social integration such as marital status, network size, and participation (59). Reproduced and modified from Holt-Lunstad et al. (59), which is an open-access article distributed under the terms of the Creative Commons Attribution License. To see this illustration in color, the reader is referred to the web version of this article at www.liebertpub.com/ars

\section{Loneliness as a Cardiovascular Risk Factor}

An early study published in 1992 showed that coronary heart disease (CHD) patients who were not married and did not have a confidant had a significantly higher 5-year incidence of mortality $(50 \%)$ than that $(18 \%)$ observed in patients with a spouse or partner (146). Two reviews about social relationships and CHD associated the degree of loneliness with the incidence and prognosis of $\mathrm{CHD}$, although the evidence was relatively weak $(3,124)$

A recent systematic review followed by a meta-analysis of 16 prospective longitudinal studies showed that loneliness and social isolation were correlated with increased risks of CHD (29\%) and stroke (32\%) (138). The association was comparable to anxiety and job stress, which are recognized risk factors for CHD (138). This finding reinforces existing evidence demonstrating that poor social connections robustly predict morbidity and mortality, and that loneliness and social isolation are additional risk factors of cardiovascular disease (CVD) (57).

\section{Hypertension}

Results from longitudinal (54) and cross-sectional (13) studies have shown the association between increased blood pressure and loneliness in older and middle-aged individuals; this association strengthens with increasing age of individuals (52). Moreover, individuals who were lonelier by one standard deviation had systolic blood pressure (SBP) that was $3.7 \mathrm{mmHg}$ greater at study initiation and was predicted to increase by $2.3 \mathrm{mmHg}$ over the next 4 years (52). Thus, these findings would predict that over 4 years, the most lonely individuals would exhibit an increase in SBP that was $14.4 \mathrm{mmHg}$ (3.6 $\mathrm{mmHg} /$ year) higher than the least lonely individuals (54). 
Increase in total peripheral resistance (TPR) is the main cause of elevated SBP in individuals up to 40 years of age, when arterial stiffness assumes a growing role (43). TPR levels are chronically increased in young adults who are lonely relative to nonlonely individuals of the same age $(13,50)$. The more rapid increase in TPR leads to premature arterial stiffening and increase of SBP (43). Consequently, lonely individuals may develop earlier or more severe structural abnormalities in resistance arteries that promote deposition of collagen and decrease elastic fiber content (54).

\section{Atherosclerosis}

There is a large body of evidence from animal studies showing that social isolation and social stress accelerate atherogenesis. Male cynomolgus monkeys exposed to social stress (e.g., via periodic reorganizing of groups with different conspecifics) and fed a diet low in fat and cholesterol developed more severe atherosclerosis of the coronary artery compared with control monkeys under nonstress conditions (maintained in stable groups) (63). The lack of significant effects of social stress on blood pressure, serum lipid, and glucose levels, or ponderosity indicated that atherogenesis in these stressed monkeys was independent of serum lipid levels (63). In female cynomolgus monkeys that consumed a moderately atherogenic diet, social deprivation by individual housing significantly increased coronary artery atherosclerosis without a change in plasma lipid concentrations (115). Similarly, Watanabe heritable hyperlipidemic rabbits (79, 96) and apolipoprotein E-knockout mice (6) housed in social isolation showed greater atherosclerotic lesion areas than those in an affiliative social environment.

Molecular mechanisms underlying the enhanced atherosclerosis in socially isolated animals may involve sympathetic nervous system (SNS) overactivation and physical inactivity, as well as enhanced vascular inflammation and oxidative stress $(79,86,87)$.

\section{Pathways Affected by Loneliness-The Molecular Link}

In a review article published in this Forum, Meyer and Wirtz addressed the molecular mechanisms linking cytokine function and HPA axis components to mitochondrial redox signaling under psychosocial stress (83). In the present article, we discuss how loneliness and social isolation affect health by activating behavioral and psychological mechanisms as well as pathophysiological pathways (Fig. 3).

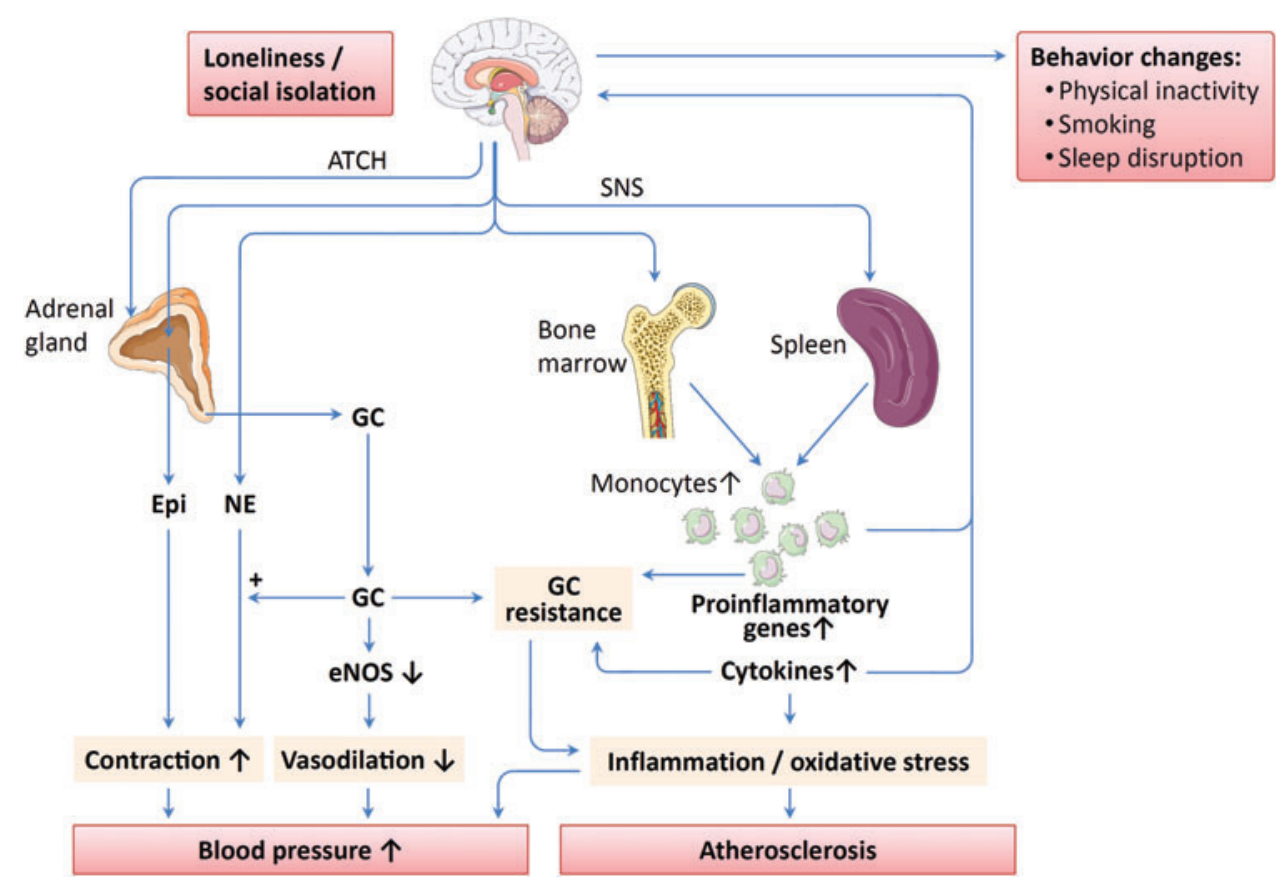

FIG. 3. Proposed mechanisms of loneliness-associated cardiovascular disease (CVD). Loneliness and social isolation lead to activation of the hypothalamic-pituitary-adrenal (HPA) axis and the sympathetic nervous system (SNS), and to behavioral alteration, including physical inactivity, smoking, and sleep disruption. SNS activation enhances monocytopoiesis in the bone marrow resulting in expansion of immature proinflammatory monocytes. In addition, SNS also stimulates monocyte egress from the spleen. Chronic social stress leads to glucocorticoid (GC) resistance, upregulation of proinflammatory gene expression, as well as enhanced cytokine production by immune cells. Cytokines, in turn, can potentiate GC resistance. The resulting enhanced inflammation and oxidative stress may be involved in atherosclerosis development and blood pressure elevation. Both proinflammatory monocytes and cytokines can traffic to the brain and amplify loneliness by inducing "sickness behaviors." Epinephrine (Epi) and norepinephrine (NE) induce vasoconstriction, an effect that is enhanced by GC. Moreover, GC reduces endothelial nitric oxide synthase (eNOS) gene expression and serine 1177 phosphorylation in endothelial cells resulting in decreased nitric oxide (NO) production and impaired vasodilation. However, the causal role of these mechanisms in the development of loneliness-associated CVDs has not been demonstrated so far, although their involvement is likely. ACTH denotes adrenocorticotropic hormone. The images of brain, bone, spleen, and monocytes used in this figure are from Servier Medical Art licensed under the Creative Commons Attribution 3.0 Unported License (111). To see this illustration in color, the reader is referred to the web version of this article at www.liebertpub.com/ars 


\section{Behavioral and psychological changes}

Social species create organizations (ranging from dyads and families to societies) beyond the individual, which have benefits such as mutual protection and assistance (12). Therefore, social isolation represents a dangerous situation, through which a socially isolated individual may react with implicit vigilance for social threats, fragmented sleep to evade predation, and increased cardiovascular activity to deal with potential assaults (12). Although these responses may be protective for short-term survival, when isolation becomes chronic, they have long-term detrimental effects on mental and physical health (12).

Social isolation and loneliness are associated with health risk behaviors such as reduced physical activity, reduced sleep quality, and smoking $(7,53,57,113,138)$. Loneliness also has been associated with depression, anxiety, dysphoria, and social withdrawal (12). Similar observations have been made in animal studies. Male adult rodents subjected to social isolation exhibit a significant decrease in physical activity and sleep quality $(11,13)$. Mice subjected to social isolation exhibited disrupted sleep and reduced slow-wave sleep (65).

\section{The HPA axis}

The major neuroendocrine systems involved in the stress response are the HPA axis and sympathetic adrenomedullary axis (11). Activation of the HPA axis is a consistent finding in lonely individuals (51), whereas the association between loneliness and increased circulating levels of catecholamines is less consistent (11).

The HPA axis plays an important role in regulating the response to stress (12). The HPA axis is the main producer of glucocorticoids, including cortisol (humans) and corticosterone (rodents). Glucocorticoid release follows the circadian rhythm, where highest levels occur in the morning and lowest levels occur in the evening. Loneliness in humans is associated with larger morning cortisol rises (1), higher circulating cortisol levels $(23,33)$, and decreased glucocorticoid receptor (GR) sensitivity $(21,25)$, indicating higher levels of HPA activation in lonely individuals (12).

Similar HPA axis activation has been observed in animal models of PSI. Chronic separation of pair-bonded prairie voles was associated with increased levels of corticosterone $(10,81,126)$, whereas chronic separation from a lowpreference partner (e.g., same-sex sibling) resulted in no increase in levels of corticosterone (10).

Glucocorticoids govern physiological functions, including immunity, metabolism, cardiovascular activity, reproductive processes, neurodegeneration, and apoptosis (11). Glucocorticoids mediate these physiological functions via rapidacting, nongenomic effects and slow-acting genomic effects. For example, stimulation of GRs in leukocytes by cortisol results in suppression of proinflammatory gene networks. However, chronic social stress induces glucocorticoid resistance (Fig. 4) in which the GR becomes less efficient in transducing glucocorticoid signals (27). Glucocorticoid resistance, in turn, leads to excessive inflammation as well as hyperactivity of corticotropin-releasing hormone and SNS pathways (94), which may contribute to development of diseases, including atherosclerosis, diabetes, neurodegeneration and tumor metastasis (11). Interestingly, CHD patients show a blunted cortisol stress response (less cortisol release in response to acute stress) (140), and depressed individuals with CHD have increased inflammatory marker expression and decreased GR expression and GR sensitivity compared with nondepressed CHD patients (89).

A variety of molecular mechanisms have been implicated in glucocorticoid resistance (Fig. 4), including GR degradation, disruption of GR translocation, and/or GR-DNA binding, as well as changes in GR phosphorylation status $(94,105,117)$. Importantly, inflammatory cytokines potentiate glucocorticoid resistance (94). As glucocorticoid resistance exacerbates inflammation and production of proinflammatory cytokines, there may exist a positive feedback mechanism in the development of glucocorticoid resistance. In addition, glucocorticoid resistance can be attenuated by $\beta$-adrenoceptor blockade in socially isolated mice, which indicates a contribution of the SNS to glucocorticoid resistance $(48,101)$.

In endothelial cells, glucocorticoids reduce nitric oxide (NO) production via endothelial NO synthase (eNOS). NO derived from eNOS is a crucial antihypertensive and antiatherosclerotic factor $(42,70)$. Both the expression level (142) and serine 1177 phosphorylation (136) of eNOS are decreased by glucocorticoid treatment. Reduced endothelial NO production represents a crucial mechanism in the development of glucocorticoid therapy-induced hypertension $(107,141,142)$. Moreover, glucocorticoids also potentiate the vasoconstricting effect of catecholamines (150). However, the contribution of these mechanisms to blood pressure elevation and atherosclerosis in lonely and socially isolated individuals remains to be determined. It is not clear whether the loneliness-associated glucocorticoid resistance also occurs in endothelial cells or is restricted to immune cells. Nevertheless, acetylcholineinduced, endothelium-dependent vasodilation is impaired in the aorta of socially isolated prairie voles (97), which suggests reduced endothelial NO production from eNOS.

\section{The SNS}

The SNS projects from the central nervous system through the splanchnic nerve directly to the adrenal medulla. This direct innervation enables a rapid response to acute stress via secretion of epinephrine (and smaller amounts of norepinephrine and dopamine) into the circulation (11). In addition, the SNS innervates the entire body, including the lymphoid system (48), and SNS nerve fibers release norepinephrine directly into the thymus, spleen, and lymph nodes (11).

Evidence for the association between loneliness and elevated catecholamine levels (44) has not been as consistently shown as the effect of loneliness on the HPA axis $(11,52)$. In humans and macaques, chronic PSI has been associated with elevated urinary levels of norepinephrine metabolites but not epinephrine (23).

Interestingly, social stress appears to be much more strongly related to local catecholamine levels in SNSinnervated tissues (e.g., thymus, spleen, lymph nodes, and tumors) than systemic catecholamine levels. For instance, poor social support and high prevalence of depression in ovarian cancer patients were associated with significantly higher norepinephrine levels in tumor tissues compared with patients with strong social networks and lower prevalence of depression. In contrast, no effect of social support on plasma norepinephrine was found in the same patient population $(75$, 76). Moreover, the high tumor norepinephrine levels were 


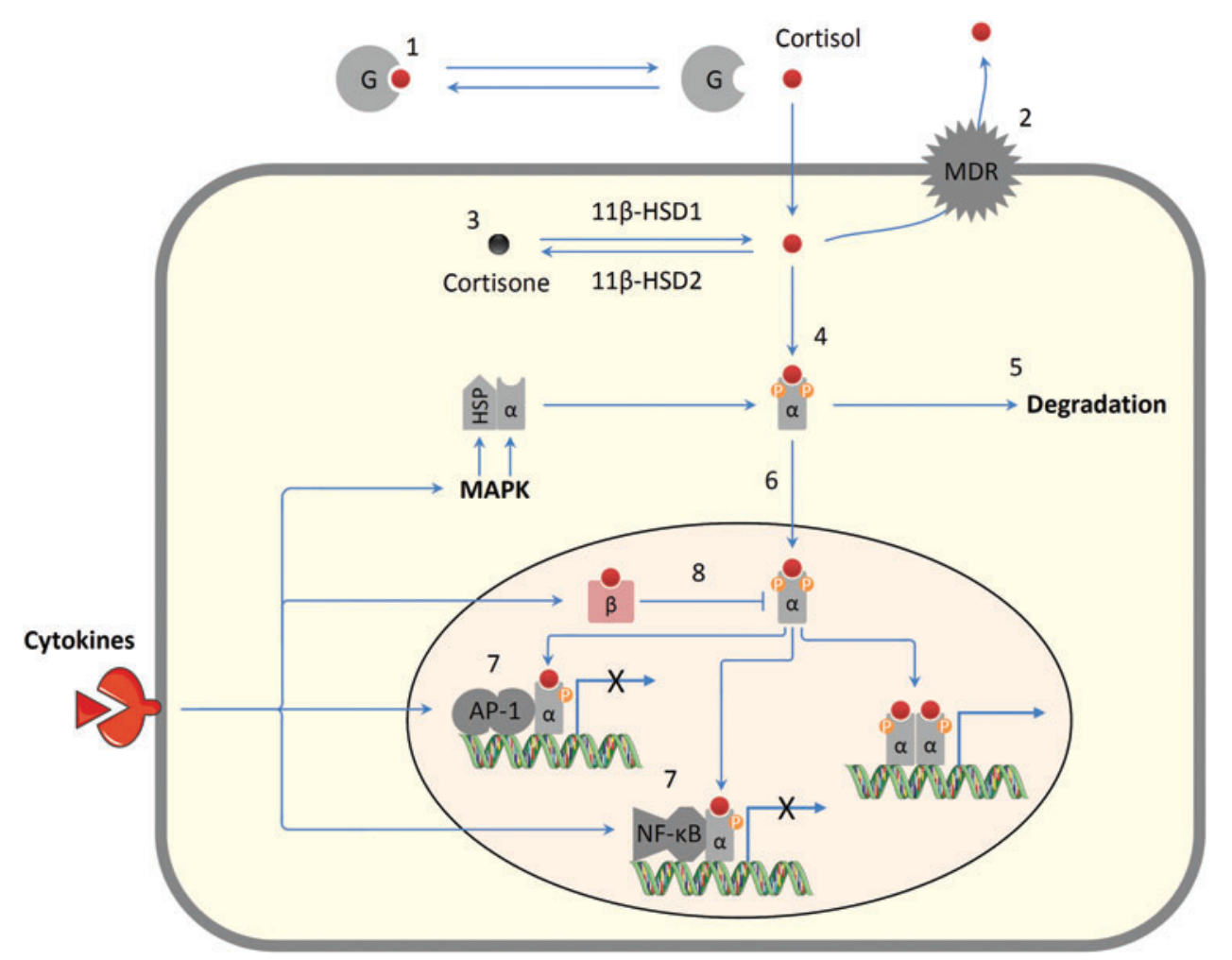

FIG. 4. Mechanisms of glucocorticoid resistance. Reduction in glucocorticoid sensitivity can be ascribed to alteration of factors that regulate glucocorticoid bioavailability and activity such as [1] increased corticosteroid-binding globulin (G); [2] increased expression of the multidrug resistance transporter (MDR pump); [3] increased expression of cortisol-inactivating enzyme 11 $\beta$-HSD-2; [4] reduced glucocorticoid binding to the glucocorticoid receptor (GR $\alpha$ ); [5] inflammasome-mediated degradation of GR $\alpha$; [6] reduced GR nuclear translocation due to phosphorylation by p38 and JNK classes of mitogenactivated protein kinase (MAPK); [7] increased GR interaction with inflammatory-related transcription factors, such as NF$\kappa \mathrm{B}$ or AP-1; and [8] increased expression of the inhibitory glucocorticoid receptor GR $\beta$. HSP, heat shock protein. X indicates inhibition of gene expression. Partly adapted from Refs. 94, 105, 117, 139. To see this illustration in color, the reader is referred to the web version of this article at www.liebertpub.com/ars

paralleled by stronger norepinephrine effects mediated by $\beta$ receptors, for example, transcription pathways that mediate inflammation, metastatic capacity, and cell proliferation (19, $28,75,76)$.

The social regulation of tissue norepinephrine levels is not only a result of functional but also structural changes. Studies in nonhuman primates have found a substantial amount of socially regulated plasticity in the innervation of lymph nodes $(120,122)$. Animals housed under unstable conditions showed catecholaminergic innervation of lymph nodes that was more than twice as dense as animals socialized under stable social conditions. These animals had an impaired antiviral immune response, normally mediated by type I interferon, which resulted in increased simian immunodeficiency virus (SIV) load (122). Given lymphoid organs' fundamental immunoregulatory role, social stress-induced innervation of lymph nodes may have a range of effects on immunity and inflammation $(120,121)$.

The SNS is also involved in upregulated production of immature and proinflammatory monocytes by the bone marrow in response to social stress, an effect that is mediated by $\beta$-adrenergic receptors (101). Social stress leads to a proinflammatory state characterized by increased monocytopoiesis and selective expansion of an immature monocyte subset (Ly6c ${ }^{\mathrm{hi}}$ and CD16 ${ }^{-}$in mice and humans, respectively) $(55,101)$.
These immature monocytes are proinflammatory, while the more mature Ly6c ${ }^{\text {lo }}$ monocytes are immunoregulatory (127).

Peripheral blood mononuclear cells (PBMCs) from young adults subjected to chronic socioeconomic stress showed total monocyte transcriptome expansion and immature proinflammatory $\mathrm{CD}^{-} 6^{-}$monocyte transcriptome expansion (101). Moreover, this proinflammatory gene expression profile was mediated by upregulation of myelopoiesis induced by the SNS (101). The bone marrow microenvironment, where hematopoiesis and differentiation of monocytes take place, is innervated by the SNS (35), which implies that mobilization of hematopoietic stem cells is regulated by the SNS $(4,64)$.

Repeated social defeat (RSD) in mice is used as a model for social disruption stress (SDR). Like SDR, RSD results in activation of the HPA axis and the SNS. RSD in mice results in increased bone marrow monocytopoiesis and Ly6c ${ }^{\text {hi }}$ monocyte accumulation in blood, spleen, bone marrow, and brain $(80,101)$. Pretreatment of mice with propranolol $(\beta$ adrenergic receptor blocker) before RSD prevented peripheral Ly $6 c^{\text {hi }}$ monocyte expansion and proinflammatory gene upregulation in monocytes from peripheral blood (101).

Interestingly, SNS activation in the spleen results in the release of primed monocytes (80). Splenomegaly and glucocorticoid resistance in $\mathrm{CD}_{11 b^{+}}$and $\mathrm{CD}_{11 \mathrm{c}^{+}}$myeloid populations of the spleen were observed in mice subjected to 
RSD (48). Pretreatment of mice with propranolol before RSD led to decreased RSD-induced plasma IL-6 and splenomegaly, and attenuated anxiety-like behavior (48).

The re-establishment of anxiety-like behavior in RSD mice in response to subthreshold stress was correlated with Ly $6 c^{\text {hi }}$ monocyte release from the spleen and accumulation in the brain. Moreover, trafficking of monocytes to the brain and anxiety-like behavior induced by subthreshold stress were prevented by splenectomy before RSD in these mice. Thus, trafficking of monocytes to the brain was associated with the recurrence of anxiety-like behavior in these RSD mice (80, 128, 147).

\section{The vagal system}

An important function of the vagal system is to prevent the detrimental effects of SNS overactivation $(18,67)$. Heart rate variability (HRV) is measured by the variation in the beat-tobeat interval $(112,133)$, which is partly modulated by the autonomic nervous system at the sinoatrial node of the heart (45, 69). High-frequency heart rate variability (HF-HRV) denotes heart rate variations associated with respiration. Respiratory sinus arrhythmia occurs when the heart rate accelerates and decelerates on inspiration and expiration, respectively (112). HF-HRV is determined by vagally mediated parasympathetic activity (112). The cardiovascular center inhibits vagal outflow during inhalation and restores vagal outflow during exhalation (112). Although the heart is dually innervated, the influence of the SNS on the heart occurs too slowly to affect beat-to-beat changes quickly (133). Therefore, HF-HRV directly measures parasympathetic control of the heart $(45,91)$.

Recent studies have suggested that positive social interactions have an effect on HF-HRV (45). Marriage was associated with greater HF-HRV (102), and happy marriages were associated with even greater HF-HRV (123). One study of 2066 male civil servants in the United Kingdom (the Whitehall cohort) found a correlation between smaller HFHRV and low social integration (56). Similarly, the effect of social integration on autonomic nervous system function was demonstrated in a recent study of students who had moved to a foreign country. The lack of social integration within the initial 5 months in the host country was correlated with a higher heart rate and lower HF-HRV (45). The results suggested that changes in autonomic nervous system function, measured by HF-HRV, may be an important link between social integration and health (45).

Studies in animal models of social isolation have suggested that HRV may be regulated by the social environment. Socially isolated prairie voles had lower HF-HRV compared with socially paired voles at baseline and during exposure to stress $(46,47)$. Exogenous oxytocin administration increased the HF-HRV of socially isolated voles to a level similar to socially paired voles (47).

Similarly, oxytocin administration to healthy young adults significantly increased both sympathetic (indexed by preejection period) and parasympathetic (indexed by HF-HRV) autonomic cardiac control (91). Importantly, the level of loneliness negatively predicted alterations in autonomic control of cardiac function induced by oxytocin treatment, which was independent of anxiety, depression, and serum markers. Lonelier individuals had lower response to oxytocin-induced effects on HF-HRV (91). Because simultaneous activation of the parasympathetic nervous system mitigates the potentially deleterious effects of heightened sympathetic output $(91,133)$, loneliness may cause a potentially healthy response (autonomic coactivation) to become harmful (selective activation of the SNS).

Hence, one mechanism by which social isolation may negatively impact health outcomes is via altered autonomic nervous system function (45). Indeed, a lower HF-HRV has been correlated with adverse health outcomes (45), including reduced cognitive function, depression, CVD, and all-cause mortality $(73,132,134,137)$.

\section{The immune system}

Social isolation and socioeconomic stress have been associated with the conserved transcriptional response to adversity (CTRA) in leukocytes, characterized by upregulation of proinflammatory gene expression and downregulation of antibody- and antiviral immunity-related genes $(25,26,101)$. Human myeloid-derived antigen-presenting cells such dendritic cells, monocytes, and B cells have been identified by transcript origin analyses as the major cellular contributors of the transcriptional response of the immune system to loneliness (24).

In lonely individuals, SNS activation (101), rather than circulating levels of cortisol, causes the shift between proand anti-inflammatory signaling $(25,101)$. Loneliness also has been correlated with elevated levels of norepinephrine metabolites (but not epinephrine) in urine (23). SNS activation enhanced myelopoiesis $(55,101)$ and concurrently regulated CTRA-related gene expression (23).

Reciprocal regulation of the leukocyte transcriptome may result in two distinct functional consequences: enhanced inflammation and an impaired antiviral response.

Monocytes are the main source of the proinflammatory function of the CTRA (101), which results from immature CD $14^{++} / \mathrm{CD} 16^{-}$monocyte subset expansion (23) and upregulated proinflammatory gene expression (24). While the number of total circulating leukocytes (24) was not significantly changed in lonely individuals, the percentage of circulating monocytes was increased and CTRA-associated gene expression was upregulated (23). Upregulation of CTRA-related gene expression in human resulted likely from selective expansion of the immature $\mathrm{CD} 14^{++} / \mathrm{CD} 16^{-}$classical monocyte subset rather than the total CD14 ${ }^{++}$monocyte population (23). Similarly, macaques with high PSI also showed upregulated circulating monocyte frequencies and percentages. Within the monocyte population, classical $\mathrm{CD} 14^{++} / \mathrm{CD} 16^{-}$monocytes were expanded, and nonclassical CD $14^{++} / \mathrm{CD} 16^{+}$monocytes were unchanged (23). Analogous to high-PSI humans, highPSI macaques showed upregulated CTRA-related gene expression in the classical CD $14^{++} / \mathrm{CD} 16^{-}$monocytes from the PBMC population (23). Moreover, circulating lymphocytes from high-PSI humans $(24,25)$ and macaques $(23)$ showed glucocorticoid resistance, including downregulated GR expression and upregulated NF- $\kappa \mathrm{B}$ expression (23).

Based on these data, Cole et al. proposed a mechanistic model in which loneliness results in an SNS-mediated expansion of myeloid-lineage cells characterized as immature, proinflammatory, and glucocorticoid resistant (23). Upregulation of proinflammatory gene expression in lonely people may be explained by glucocorticoid resistance even with 
concurrently elevated cortisol levels, as the anti-inflammatory effects of endogenous glucocorticoids are diminished because of impaired GR signaling (23). The resulting long-term inflammation may represent a key mechanism in the development of loneliness-associated chronic diseases such as atherosclerosis, cancer, and neurodegeneration (23).

The other part of the leukocyte CTRA, namely, reduced type I interferon activity and reduced antibody-related gene expression, likely comes from dendritic cells, which produce interferon, and B lymphocytes, respectively $(23,24)$. This may lead to impaired immunity as the functional consequence. At baseline, high-PSI macaques showed downregulated PBMC mRNA levels of interferon genes compared to controls. After infection with SIV, interferon gene expression was significantly upregulated in controls but not in high-PSI animals. High-PSI macaques also showed weaker suppression of SIV gene expression in PBMCs, increased viral load in plasma and cerebrospinal fluid, and decreased titers of anti-SIV IgG antibodies (23).

Importantly, CTRA gene expression may reciprocally affect loneliness. In lonely individuals, the immature proinflammatory monocytes can traffic into the brain, leading to anxiety and altered social behavior. Moreover, release of proinflammatory cytokines in the brain may promote "sickness behaviors," which include affective, perceptual, and motivational processes that could augment loneliness and decrease the desire for social interaction, creating a vicious cycle $(22,23)$. As mentioned above, this positive feedback loop involves trafficking of monocytes to the brain $(80,143,147)$.

\section{Oxidative stress}

Disturbed redox homeostasis in oxidative distress may represent a key molecular link from chronic psychosocial stress to CHD (116). Social isolation induces oxidative stress in the brain and in peripheral tissues. In the brain, oxidative stress was shown to be a crucial mechanism triggering HPA activation. In the periphery, oxidative stress may be the result of social isolation-induced changes in the HPA, SNS, and the immune system as detailed above. Indeed, a large-scale study involving 2858 subjects showed that markers of the HPA axis, SNS, and inflammation were associated with oxidative damage in a dose-response manner (9).

Social isolation rearing of rats (individual housing starting at the age of 21 days) led to an increase in oxidative stress in the hypothalamus and the prefrontal cortex $(20,109)$. Importantly, the elevation in oxidative stress markers in the hypothalamus after 2 weeks was an early pathological event that preceded the increase of corticotropin-releasing factor levels in the hypothalamus and adrenocorticotropic hormone levels in the plasma at 4 weeks, and increased corticosterone levels in plasma and saliva after 7 weeks (20). Thus, the early increase of oxidative stress likely triggered the stress response and HPA-axis activation (20).

NADPH oxidase (NOX) enzymes comprise a family of membrane proteins that generate reactive oxygen species (ROS) (108). Among the NOX enzymes found in the brain (NOX1, NOX2, NOX3, and NOX4), NOX2 has a critical role in social isolation $(20,108)$. Social isolation in rats led to upregulation of NOX2 and its components (p22phox, p67phox, p47phox, and p40phox) in the brain (109). Treatment of rats with the antioxidant/NOX inhibitor apocynin (starting after 4 weeks of social isolation) stopped the progression of HPA-axis activation induced by social isolation (20). Rats that had a loss-of-function mutation in the NOX2 subunit p47phox were completely protected from changes in the neuroendocrine profile and behavior induced by social isolation (20). These results suggested that NOX2-derived oxidative stress in the hypothalamus was a causal factor in social isolation-induced HPA activation and in the development of anxiety-like symptoms.

The relationship between oxidative stress and the HPA axis in social isolation seems to be bidirectional. As mentioned above, NOX2-mediated oxidative stress in the hippocampus lies upstream of social isolation-induced changes in the HPA axis. On the contrary, glucocorticoids derived from the HPA axis also have an impact on NOX expression and activity (108). In hippocampal neurons, glucocorticoids have been shown to upregulate the expression (151) and activity (66) of NOX. There is also evidence that social isolation may induce oxidative stress in the prefrontal cortex and hippocampus by inhibiting antioxidant enzymes $(39,108)$. However, these results are inconsistent (Table 1).

Social isolation-induced oxidative stress also has been observed in the vasculature. For example, individually caged Watanabe heritable hyperlipidemic rabbits have a higher NOX activity in the aortic arch (86). As NOXs are the main producers of ROS in the vasculature $(42,71,72)$, the increased vascular activity of NOX may promote atherosclerosis development by inducing oxidative stress. Mechanistically, social isolation-induced HPA activation, GR resistance, SNS activation, and inflammation, as described above, may all contribute to vascular oxidative stress. Although a short incubation for $24 \mathrm{~h}$ with glucocorticoids was reported to reduce p22phox expression in human smooth muscle cells, chronic

Table 1. Reported Changes in Antioxidant Enzymes in the Hippocampus of Socially Isolated Rats

\begin{tabular}{|c|c|c|c|c|}
\hline Animals & $\begin{array}{l}\text { Age at } \\
\text { isolation }\end{array}$ & $\begin{array}{c}\text { Duration of } \\
\text { isolation (weeks) }\end{array}$ & Antioxidant systems & Reference \\
\hline Male rats & 3 weeks & 8 & SOD $\downarrow ;$ catalase $\downarrow$; GPx $\downarrow$ & (114) \\
\hline Male rats & $2-3$ months & 3 & SOD1 $\leftrightarrow ;$ SOD2 $\leftrightarrow$ & $(38,40)$ \\
\hline Male rats & 2.5 months & 3 & $\mathrm{GSH} \downarrow ; \mathrm{MDA} \leftrightarrow ; \mathrm{SOD} \leftrightarrow$ & $(152)$ \\
\hline Male rats & 3 months & 3 & SOD $\uparrow ;$ catalase $\uparrow$ & $(95)$ \\
\hline Male rats & 3 months & 3 & $\begin{array}{l}\text { SOD } \leftrightarrow ; \text { catalase } \leftrightarrow ; \text { GPx expression } \leftrightarrow ; \\
\text { GPx activity } \downarrow ; \text { GLR expression } \uparrow ; \text { GLR activity } \leftrightarrow\end{array}$ & $(32)$ \\
\hline Male rats & 3 months & 3 & GCLM $\uparrow ;$ GSTA $3 \leftrightarrow ;$ GLR $\leftrightarrow$ & $(31)$ \\
\hline
\end{tabular}

GCLM, glutamate cysteine ligase modifier subunit; GLR, glutathione reductase; GPx, glutathione peroxidase; GSTA3, glutathione Stransferase A3; MDA, malondialdehyde; SOD, superoxide dismutase; $\downarrow$, reduction; $\uparrow$, increase; $\leftrightarrow$, no significant changes. 
dexamethasone treatment has been shown to upregulate NOX1 expression in rat smooth muscle cells $(77,118)$.

Exogenous administration of the sympathetic neurotransmitter norepinephrine in rats was shown to increase systemic ROS production by stimulating circulating leukocytes (110). Conversely, ROS stimulated central and peripheral SNS activity (16). Treatment of freshly isolated human PBMC with norepinephrine increased the gene expression of NOX components and intracellular superoxide production, effects that are preferentially mediated by $\alpha_{2}$-receptors (30). Moreover, norepinephrine treatment also enhances adhesion of $\mathrm{CD} 14^{+}$ monocytes to endothelial cells (30). These results are consistent with the observation in humans that loneliness results in an SNS-mediated increase of proinflammatory immature monocytes (23). Indeed, proinflammatory monocytes may have a crucial role in CVD pathogenesis by infiltrating into the vascular wall, causing local inflammation and oxidative stress, as shown in the mouse model of angiotensin IIinduced hypertension (144).

Thus, it is possible that environmental stressor-stimulated pathways, triggered by social isolation, traffic noise, or air pollution $(84,85,145)$, may converge into a common mechanism, that is, inducing vascular dysfunction and CVD by causing vascular oxidative stress and inflammation.

\section{Interventional and Therapeutic Strategies}

Because of the detrimental effects of loneliness on physical and mental health and the growing prevalence, there is an urgent need for the development of interventional and therapeutic strategies. Currently, there is no pharmacological treatment for loneliness (14). There are, however, approaches that can mitigate loneliness or alleviate the damaging effects of loneliness on health.

\section{Interventions to reduce loneliness}

When Engel proposed the biopsychosocial model of disease 40 years ago, the dominant model of disease at that time was biomedical, leaving no room within its framework for the social, psychological, and behavioral dimensions of illness (36). Nowadays, the contribution of such factors to disease is well accepted in the scientific community. Moreover, corresponding intervention strategies have been developed in the past decades. As early as in 1983, Ornish et al. showed that a short-term intervention consisting of stress management training and dietary changes could improve cardiovascular status in CHD patients (93).

In particular, interventions aimed to mitigate loneliness include strategies to improve social skills, enhance social support, increase opportunities for social contact, and address maladaptive social cognition (15). A recent meta-analysis demonstrated that the use of cognitive behavioral therapy to address maladaptive social cognition was most effective for reducing loneliness (78). Other approaches such as meditation, qigong, tai chi, yoga, and promoting purpose and meaning in life may reduce the detrimental effects of loneliness on health $(22,26,29,41)$.

\section{Interventions to reduce the health effects of loneliness}

Besides interventions to reduce loneliness, it also is important to develop therapeutic strategies to prevent the detrimental effects of loneliness on health, because current loneliness reduction interventions are not always successful and are not equally effective for every individual. The following potential strategies are proposed based on the pathogenic mechanisms summarized above.

Allopregnanolone. Given the important role of the HPA axis activation in chronic loneliness, modulation of the HPA axis may represent a rational strategy to treat lonelinessassociated disorders. Animal studies have demonstrated that $3 \alpha, 5 \alpha$-tetrahydroprogesterone (allopregnanolone [ALLO]) decreased stress-induced activation of the HPA axis and facilitated recovery from stressful events (14).

ALLO is a progesterone-derived, endogenous neuroactive steroid in the brain $(14,15)$. It is a potent modulator of the $\gamma$ aminobutyric acid $\left(\mathrm{GABA}_{\mathrm{A}}\right)$ receptor complex and has powerful antianxiety, anesthetic, and anticonvulsant properties (14). Whereas acute stress increases ALLO levels, repeated stress results in decreased serum levels of ALLO, which suggests that the chronic stress-induced hyperactivation of the HPA axis is partly attributable to a downregulation of ALLO synthesis (14). Indeed, ALLO specifically regulates the functions of the HPA axis (8).

Recent reports in animal models demonstrated that ALLO has an important role in social isolation. Individual housing of adult male mice reduced ALLO levels, which was attributable to downregulation of the rate-limiting enzyme $5 \alpha$-reductase type I in ALLO biosynthesis. Downregulation occurred specifically in selected neurons of the basolateral amygdala, hippocampus, and medial prefrontal cortex $(2,34,98)$. Importantly, administration of exogenous ALLO can normalize social isolation-induced HPA dysfunction $(8,103)$ and behavioral effects $(37,88,98,99)$. Similar results have been obtained with ganaxolone, a synthetic analog of ALLO (100).

Interestingly, the social isolation-induced behavioral effects can also be normalized with some selective serotonin reuptake inhibitors at doses far below those required to block serotonin reuptake $(37,88,90,98,99)$. These results indicate that such drugs may lead to improvement in behaviors not by inhibiting serotonin reuptake, but rather by elevating corticolimbic levels of ALLO.

Based on the animal studies, Cacioppo et al. hypothesized that ALLO has an important role in loneliness in humans (14, 15). The potential of ALLO, ALLO precursors, and ALLO analogs as novel treatments for loneliness needs to be tested in clinical studies (14).

$\beta$-Blockers. Direct SNS innervation of the spleen and primary and secondary lymphoid organs links behavioral processes to regulation of the immune system (120). Epinephrine and norepinephrine stimulate receptors belonging to two major subclasses: the $\alpha$ - and the $\beta$-adrenergic receptors (48). Most immune cells have $\alpha_{1}$ and $\beta_{2}$ receptors, which typically exert opposite effects (Table 2). Under homeostatic conditions, the signals mediated by $\beta_{2}$ receptors usually predominate (5). Activation of $\beta$-adrenergic receptors by catecholamines increases the production of proinflammatory cytokines in several cell types (48). $\beta_{2}$ receptor activation in mouse macrophages has been shown to upregulate IL- $1 \beta$ and IL-6 expression, which promotes a proinflammatory immune response (131). 
Table 2. Expression and Function of Adrenergic Receptors in Immune Cells

\begin{tabular}{|c|c|c|c|}
\hline Cell type & $\beta_{2}$ & $\alpha_{1}$ & Reference \\
\hline Neutrophils & $\begin{array}{l}\downarrow \text { neutrophil interaction with endothelial cells; } \\
\quad \downarrow \text { phagocytosis; } \downarrow \text { lysosomal enzyme release; } \\
\quad \downarrow \text { respiratory burst }\end{array}$ & $\begin{array}{l}\uparrow \text { neutrophils release into the } \\
\text { circulation }\end{array}$ & $(5,106)$ \\
\hline $\begin{array}{l}\text { Monocytes/ } \\
\text { macrophages }\end{array}$ & Both pro- and anti-inflammatory effects reported & $\begin{array}{l}\text { Proinflammatory effects (monocytes } \\
\text { acquire } \alpha_{1} \text { receptor after homing) }\end{array}$ & $(5,106)$ \\
\hline NK cells & $\begin{array}{l}\text { NK cell in blood ( } \uparrow \text { acutely, } \downarrow \text { chronically); both } \\
\text { increased and decreased NK activities have been } \\
\text { reported }\end{array}$ & $\uparrow \mathrm{NK}$ cytotoxicity & $(5,106)$ \\
\hline $\mathrm{DC}$ & $\begin{array}{l}\downarrow \mathrm{Ag} \text { protein cross-presentation; } \downarrow \text { IL-12; shift from } \\
\text { Th1 to Th2-type immune response }\end{array}$ & Stimulation of DC migration & $(5,106)$ \\
\hline Th0 cells & $\begin{array}{l}\uparrow I F N-\gamma \text { and Th1-cell differentiation (in the } \\
\text { presence of TNF- } \alpha \text { and IL-12); } \uparrow \text { Th2-cell } \\
\text { differentiation (in the presence of IL-4 and IL- } \\
\text { 10) }\end{array}$ & - & $(5)$ \\
\hline Th1 cells & $\downarrow$ IFN- $\gamma$ (negative feedback) & - & (5) \\
\hline Th2 cells & - (epigenetic loss of $\beta_{2}$ receptors) & - & $(5,17)$ \\
\hline $\mathrm{B}$ cells & $\begin{array}{l}\text { Dependent on activation state of } \mathrm{B} \text { cell }(\uparrow \operatorname{IgG} 1 / \mathrm{IgE} \\
\text { production during Ag processing; } \uparrow \mathrm{IgG} 2 \text { after } \\
\mathrm{Ag} \text { processing; } \downarrow \mathrm{Ab} \text { production by plasma cells) }\end{array}$ & - & (5) \\
\hline
\end{tabular}

DC, dendritic cells; NK, natural killer.

The SNS upregulates production of immature, proinflammatory monocytes in the bone marrow, which is mediated via $\beta$-adrenergic receptors $(48,101)$. Moreover, $\beta$-adrenergic receptor-mediated mechanism is involved in social stressinduced glucocorticoid resistance $(48,101)$ and monocyte trafficking from the spleen $(48,80,147)$.

When fed a cholesterol-containing diet and housed in periodically reorganized social groupings (i.e., social disruption), highly aggressive and competitive (dominant) male cynomolgus monkeys developed exacerbated coronary artery atherosclerosis (62). Pharmacological treatment with the $\beta$ blocker propranolol prevented the exacerbation of atherosclerosis caused by the unstable social environment (62). Importantly, the antiatherogenic effects of propranolol on dominant male monkeys were independent of resting heart rate, blood pressure, and serum lipid concentrations (62).

Given the complex effects of $\beta_{2}$ receptors in different immune cells and in other cell types, the therapeutic potential of $\beta$ blockers for loneliness-associated diseases cannot be predicted at this stage, which warrants additional studies, especially in animal models of social isolation.

Oxytocin. Oxytocin is a neuropeptide produced in the hypothalamus, which promotes a strong desire for social affiliation (15). Besides the traditionally known role in uterine contraction, oxytocin is suggested to be a stress-responsive hormone that exerts a regulatory influence on the HPA axis (96). Moreover, the oxytocin receptor is expressed on major vascular cells, including endothelial cells, vascular smooth muscle cells and also macrophages $(61,129)$. In vitro experiments showed that oxytocin reduced NADPH-oxidase activity and inflammatory cytokine secretion by macrophages and endothelial cells (129). Chronic oxytocin administration attenuated atherosclerosis in Watanabe heritable hyperlipidemic rabbits $(129,130)$ and in socially isolated apolipoprotein E-knockout mice (87).

In humans, oxytocin administration promoted prosocial behaviors such as affiliation and trust, and influenced auto- nomic cardiac control $(15,91)$. However, findings have been inconsistent and negative effects have been reported (15). Thus, additional research is required to examine the therapeutic potential of oxytocin in the treatment of chronic loneliness (15).

NOX inhibitors. As discussed above, oxidative stress is involved in different steps of social isolation-induced pathology. Oxidative stress triggers HPA activation (20), potentiates SNS activity (16), and promotes vascular damage. The role of antioxidant enzymes in this scenario is uncertain (Table 1). In contrast, NOX seems to play a key role. Therefore, NOX inhibitors may be of therapeutic interest.

Moreover, NOX inhibition may be a potential strategy to improve resilience. In this context, resilience explains how and why some individuals live in a state of chronic loneliness and yet do not develop mental illness (108). A loss-offunction polymorphism in the p47phox subunit of NOX completely prevented behavioral and neuroendocrine changes typically associated with social isolation in rats (20). Thus, NOX may be a crucial candidate target molecule for developing approaches to improve positive adaptation, and to maintain or regain mental health despite experiencing chronic loneliness or social isolation.

\section{Summary and Future Directions}

Robust evidence supports the concept that loneliness and social isolation increase morbidity and mortality, and should be included as a risk factor for CVD. Chronic social stress is associated with activation of the SNS and the HPA axis resulting in selective expansion of proinflammatory monocytes, enhanced expression of cytokines, and glucocorticoid resistance. These mechanisms likely contribute to the increased risk of lonely individuals developing CVD. Their involvement, however, has not been proven so far and needs to be verified in future studies. 


\section{Acknowledgments}

Grants from the Deutsche Forschungsgemeinschaft (DFG; LI-1042/1-1 and LI-1042/3-1) and the intramural fund (Stufe I) of the Johannes Gutenberg University Medical Center Mainz supported the original work from the authors' laboratory included in this review.

\section{References}

1. Adam EK, Hawkley LC, Kudielka BM, and Cacioppo JT. Day-to-day dynamics of experience-cortisol associations in a population-based sample of older adults. Proc Natl Acad Sci U S A 103: 17058-17063, 2006.

2. Agis-Balboa RC, Pinna G, Pibiri F, Kadriu B, Costa E, and Guidotti A. Down-regulation of neurosteroid biosynthesis in corticolimbic circuits mediates social isolationinduced behavior in mice. Proc Natl Acad Sci U S A 104: 18736-18741, 2007.

3. Barth J, Schneider S, and von Kanel R. Lack of social support in the etiology and the prognosis of coronary heart disease: a systematic review and meta-analysis. Psychosom Med 72: 229-238, 2010.

4. Beiermeister KA, Keck BM, Sifri ZC, ElHassan IO, Hannoush EJ, Alzate WD, Rameshwar P, Livingston DH, and Mohr AM. Hematopoietic progenitor cell mobilization is mediated through beta- 2 and beta- 3 receptors after injury. J Trauma 69: 338-343, 2010.

5. Bellinger DL and Lorton D. Autonomic regulation of cellular immune function. Auton Neurosci 182: 15-41, 2014.

6. Bernberg E, Andersson IJ, Gan LM, Naylor AS, Johansson ME, and Bergstrom G. Effects of social isolation and environmental enrichment on atherosclerosis in ApoE $^{-/-}$mice. Stress 11: 381-389, 2008.

7. Beutel ME, Klein EM, Brahler E, Reiner I, Junger C, Michal M, Wiltink J, Wild PS, Münzel T, Lackner KJ, and Tibubos AN. Loneliness in the general population: prevalence, determinants and relations to mental health. BMC Psychiatry 17: 97, 2017.

8. Biggio G, Pisu MG, Biggio F, and Serra M. Allopregnanolone modulation of HPA axis function in the adult rat. Psychopharmacology (Berl) 231: 3437-3444, 2014.

9. Black CN, Bot M, Revesz D, Scheffer PG, and Penninx B. The association between three major physiological stress systems and oxidative DNA and lipid damage. Psychoneuroendocrinology 80: 56-66, 2017.

10. Bosch OJ, Nair HP, Ahern TH, Neumann ID, and Young LJ. The CRF system mediates increased passive stresscoping behavior following the loss of a bonded partner in a monogamous rodent. Neuropsychopharmacology 34: 1406-1415, 2009.

11. Cacioppo JT, Cacioppo S, Capitanio JP, and Cole SW. The neuroendocrinology of social isolation. Annu Rev Psychol 66: 733-767, 2015.

12. Cacioppo JT, Cacioppo S, Cole SW, Capitanio JP, Goossens L, and Boomsma DI. Loneliness across phylogeny and a call for comparative studies and animal models. Perspect Psychol Sci 10: 202-212, 2015.

13. Cacioppo JT, Hawkley LC, Crawford LE, Ernst JM, Burleson MH, Kowalewski RB, Malarkey WB, Van Cauter E, and Berntson GG. Loneliness and health: potential mechanisms. Psychosom Med 64: 407-417, 2002.

14. Cacioppo S and Cacioppo JT. Why may allopregnanolone help alleviate loneliness? Med Hypotheses 85: 947-952, 2015.
15. Cacioppo S, Grippo AJ, London S, Goossens L, and Cacioppo JT. Loneliness: clinical import and interventions. Perspect Psychol Sci 10: 238-249, 2015.

16. Campese VM, Ye S, Zhong H, Yanamadala V, Ye Z, and Chiu J. Reactive oxygen species stimulate central and peripheral sympathetic nervous system activity. Am $J$ Physiol Heart Circ Physiol 287: H695-H703, 2004.

17. Case AJ and Zimmerman MC. Sympathetic-mediated activation versus suppression of the immune system: consequences for hypertension. J Physiol 594: 527-536, 2016.

18. Cherkas A, Abrahamovych O, Golota S, Nersesyan A, Pichler C, Serhiyenko V, Knasmuller S, Zarkovic N, and Eckl P. The correlations of glycated hemoglobin and carbohydrate metabolism parameters with heart rate variability in apparently healthy sedentary young male subjects. Redox Biol 5: 301-307, 2015.

19. Coelho M, Soares-Silva C, Brandao D, Marino F, Cosentino $\mathrm{M}$, and Ribeiro L. beta-Adrenergic modulation of cancer cell proliferation: available evidence and clinical perspectives. J Cancer Res Clin Oncol 143: 275-291, 2017.

20. Colaianna M, Schiavone S, Zotti M, Tucci P, Morgese MG, Backdahl L, Holmdahl R, Krause KH, Cuomo V, and Trabace L. Neuroendocrine profile in a rat model of psychosocial stress: relation to oxidative stress. Antioxid Redox Signal 18: 1385-1399, 2013.

21. Cole SW. Social regulation of leukocyte homeostasis: the role of glucocorticoid sensitivity. Brain Behav Immun 22: 1049-1055, 2008.

22. Cole SW. Human social genomics. PLoS Genet 10: e1004601, 2014.

23. Cole SW, Capitanio JP, Chun K, Arevalo JM, Ma J, and Cacioppo JT. Myeloid differentiation architecture of leukocyte transcriptome dynamics in perceived social isolation. Proc Natl Acad Sci U S A 112: 15142-15147, 2015.

24. Cole SW, Hawkley LC, Arevalo JM, and Cacioppo JT. Transcript origin analysis identifies antigen-presenting cells as primary targets of socially regulated gene expression in leukocytes. Proc Natl Acad Sci U S A 108: 3080-3085, 2011.

25. Cole SW, Hawkley LC, Arevalo JM, Sung CY, Rose RM, and Cacioppo JT. Social regulation of gene expression in human leukocytes. Genome Biol 8: R189, 2007.

26. Cole SW, Levine ME, Arevalo JM, Ma J, Weir DR, and Crimmins EM. Loneliness, eudaimonia, and the human conserved transcriptional response to adversity. Psychoneuroendocrinology 62: 11-17, 2015.

27. Cole SW, Mendoza SP, and Capitanio JP. Social stress desensitizes lymphocytes to regulation by endogenous glucocorticoids: insights from in vivo cell trafficking dynamics in rhesus macaques. Psychosom Med 71: 591-597, 2009.

28. Cole SW, Nagaraja AS, Lutgendorf SK, Green PA, and Sood AK. Sympathetic nervous system regulation of the tumour microenvironment. Nat Rev Cancer 15: 563-572, 2015.

29. Creswell JD, Irwin MR, Burklund LJ, Lieberman MD, Arevalo JM, Ma J, Breen EC, and Cole SW. MindfulnessBased Stress Reduction training reduces loneliness and pro-inflammatory gene expression in older adults: a small randomized controlled trial. Brain Behav Immun 26: 1095-1101, 2012.

30. Deo SH, Jenkins NT, Padilla J, Parrish AR, and Fadel PJ. Norepinephrine increases NADPH oxidase-derived su- 
peroxide in human peripheral blood mononuclear cells via alpha-adrenergic receptors. Am J Physiol Regul Integr Comp Physiol 305: R1124-R1132, 2013.

31. Djordjevic J, Djordjevic A, Adzic M, Mitic M, Lukic I, and Radojcic MB. Alterations in the Nrf2-Keap1 signaling pathway and its downstream target genes in rat brain under stress. Brain Res 1602: 20-31, 2015.

32. Djordjevic J, Djordjevic A, Adzic M, and Radojcic MB. Chronic social isolation compromises the activity of both glutathione peroxidase and catalase in hippocampus of male wistar rats. Cell Mol Neurobiol 30: 693-700, 2010.

33. Doane LD and Adam EK. Loneliness and cortisol: momentary, day-to-day, and trait associations. Psychoneuroendocrinology 35: 430-441, 2010.

34. Dong E, Matsumoto K, Uzunova V, Sugaya I, Takahata $\mathrm{H}$, Nomura $\mathrm{H}$, Watanabe $\mathrm{H}$, Costa $\mathrm{E}$, and Guidotti A. Brain 5alpha-dihydroprogesterone and allopregnanolone synthesis in a mouse model of protracted social isolation. Proc Natl Acad Sci U S A 98: 2849-2854, 2001.

35. Elenkov IJ, Wilder RL, Chrousos GP, and Vizi ES. The sympathetic nerve-an integrative interface between two supersystems: the brain and the immune system. Pharmacol Rev 52: 595-638, 2000.

36. Engel GL. The need for a new medical model: a challenge for biomedicine. Science 196: 129-136, 1977.

37. Evans J, Sun Y, McGregor A, and Connor B. Allopregnanolone regulates neurogenesis and depressive/ anxiety-like behaviour in a social isolation rodent model of chronic stress. Neuropharmacology 63: 1315-1326, 2012.

38. Filipovic D and Pajovic SB. Differential regulation of CuZnSOD expression in rat brain by acute and/or chronic stress. Cell Mol Neurobiol 29: 673-681, 2009.

39. Filipovic D, Todorovic N, Bernardi RE, and Gass P. Oxidative and nitrosative stress pathways in the brain of socially isolated adult male rats demonstrating depressive- and anxiety-like symptoms. Brain Struct Funct 222: 1-20, 2017.

40. Filipovic D, Zlatkovic J, and Pajovic SB. The effect of acute or/and chronic stress on the MnSOD protein expression in rat prefrontal cortex and hippocampus. Gen Physiol Biophys 28 Spec No: 53-61, 2009.

41. Fong SS, Wong JY, Chung LM, Yam TT, Chung JW, Lee YM, Chow LP, Luk WS, and Ng SS. Changes in heart-rate variability of survivors of nasopharyngeal cancer during Tai Chi Qigong practice. J Phys Ther Sci 27: 1577-1579, 2015.

42. Forstermann U, Xia N, and Li H. Roles of vascular oxidative stress and nitric oxide in the pathogenesis of atherosclerosis. Circ Res 120: 713-735, 2017.

43. Franklin SS, Gustin W, 4th, Wong ND, Larson MG, Weber MA, Kannel WB, and Levy D. Hemodynamic patterns of age-related changes in blood pressure. The Framingham Heart Study. Circulation 96: 308-315, 1997.

44. Gavrilovic L, Spasojevic N, and Dronjak S. Chronic individual housing-induced stress decreased expression of catecholamine biosynthetic enzyme genes and proteins in spleen of adult rats. Neuroimmunomodulation 17: 265269, 2010.

45. Gouin JP, Zhou B, and Fitzpatrick S. Social integration prospectively predicts changes in heart rate variability among individuals undergoing migration stress. Ann Behav Med 49: 230-238, 2015.

46. Grippo AJ, Lamb DG, Carter CS, and Porges SW. Social isolation disrupts autonomic regulation of the heart and influences negative affective behaviors. Biol Psychiatry 62: 1162-1170, 2007.

47. Grippo AJ, Trahanas DM, Zimmerman RR, 2nd, Porges $\mathrm{SW}$, and Carter CS. Oxytocin protects against negative behavioral and autonomic consequences of long-term social isolation. Psychoneuroendocrinology 34: 1542-1553, 2009.

48. Hanke ML, Powell ND, Stiner LM, Bailey MT, and Sheridan JF. Beta adrenergic blockade decreases the immunomodulatory effects of social disruption stress. Brain Behav Immun 26: 1150-1159, 2012.

49. Hansen $T$ and Slagsvold B. Late-life loneliness in 11 european countries: results from the generations and gender survey. Soc Indic Res 129: 445-464, 2016.

50. Hawkley LC, Burleson MH, Berntson GG, and Cacioppo JT. Loneliness in everyday life: cardiovascular activity, psychosocial context, and health behaviors. J Pers Soc Psychol 85: 105-120, 2003.

51. Hawkley LC, Cole SW, Capitanio JP, Norman GJ, and Cacioppo JT. Effects of social isolation on glucocorticoid regulation in social mammals. Horm Behav 62: 314-323, 2012.

52. Hawkley LC, Masi CM, Berry JD, and Cacioppo JT. Loneliness is a unique predictor of age-related differences in systolic blood pressure. Psychol Aging 21: 152-164, 2006.

53. Hawkley LC, Thisted RA, and Cacioppo JT. Loneliness predicts reduced physical activity: cross-sectional \& longitudinal analyses. Health Psychol 28: 354-363, 2009.

54. Hawkley LC, Thisted RA, Masi CM, and Cacioppo JT. Loneliness predicts increased blood pressure: 5-year cross-lagged analyses in middle-aged and older adults. Psychol Aging 25: 132-141, 2010.

55. Heidt T, Sager HB, Courties G, Dutta P, Iwamoto Y, Zaltsman A, von Zur Muhlen C, Bode C, Fricchione GL, Denninger J, Lin CP, Vinegoni C, Libby P, Swirski FK, Weissleder R, and Nahrendorf M. Chronic variable stress activates hematopoietic stem cells. Nat Med 20: 754-758, 2014.

56. Hemingway H, Shipley M, Brunner E, Britton A, Malik $\mathrm{M}$, and Marmot M. Does autonomic function link social position to coronary risk? The Whitehall II study. Circulation 111: 3071-3077, 2005.

57. Holt-Lunstad J and Smith TB. Loneliness and social isolation as risk factors for CVD: implications for evidencebased patient care and scientific inquiry. Heart 102: 987-989, 2016.

58. Holt-Lunstad J, Smith TB, Baker M, Harris T, and Stephenson D. Loneliness and social isolation as risk factors for mortality: a meta-analytic review. Perspect Psychol Sci 10: 227-237, 2015.

59. Holt-Lunstad J, Smith TB, and Layton JB. Social relationships and mortality risk: a meta-analytic review. PLoS Med 7: e1000316, 2010.

60. House JS, Landis KR, and Umberson D. Social relationships and health. Science 241: 540-545, 1988.

61. Jankowski M, Wang D, Hajjar F, Mukaddam-Daher S, McCann SM, and Gutkowska J. Oxytocin and its receptors are synthesized in the rat vasculature. Proc Natl Acad Sci U S A 97: 6207-6211, 2000.

62. Kaplan JR, Manuck SB, Adams MR, Weingand KW, and Clarkson TB. Inhibition of coronary atherosclerosis by propranolol in behaviorally predisposed monkeys fed an atherogenic diet. Circulation 76: 1364-1372, 1987.

63. Kaplan JR, Manuck SB, Clarkson TB, Lusso FM, Taub DM, and Miller EW. Social stress and atherosclerosis in normocholesterolemic monkeys. Science 220: 733-735, 1983. 
64. Katayama Y, Battista M, Kao WM, Hidalgo A, Peired AJ, Thomas SA, and Frenette PS. Signals from the sympathetic nervous system regulate hematopoietic stem cell egress from bone marrow. Cell 124: 407-421, 2006.

65. Kaushal N, Nair D, Gozal D, and Ramesh V. Socially isolated mice exhibit a blunted homeostatic sleep response to acute sleep deprivation compared to socially paired mice. Brain Res 1454: 65-79, 2012.

66. Kawakami-Mori F, Shimosawa T, Mu S, Wang H, Ogura S, Yatomi Y, and Fujita T. NADPH oxidase-mediated Rac1 GTP activity is necessary for nongenomic actions of the mineralocorticoid receptor in the CA1 region of the rat hippocampus. Am J Physiol Endocrinol Metab 302: E425E432, 2012.

67. Kemp AH and Quintana DS. The relationship between mental and physical health: insights from the study of heart rate variability. Int J Psychophysiol 89: 288-296, 2013.

68. Kross E, Verduyn P, Demiralp E, Park J, Lee DS, Lin N, Shablack H, Jonides J, and Ybarra O. Facebook use predicts declines in subjective well-being in young adults. PLoS One 8: e69841, 2013.

69. Levy MN. Autonomic interactions in cardiac control. Ann N Y Acad Sci 601: 209-221, 1990.

70. Li H and Forstermann U. Nitric oxide in the pathogenesis of vascular disease. J Pathol 190: 244-254, 2000.

71. Li H, Horke S, and Forstermann U. Oxidative stress in vascular disease and its pharmacological prevention. Trends Pharmacol Sci 34: 313-319, 2013.

72. Li H, Horke S, and Forstermann U. Vascular oxidative stress, nitric oxide and atherosclerosis. Atherosclerosis 237: 208-219, 2014.

73. Liao D, Carnethon M, Evans GW, Cascio WE, and Heiss G. Lower heart rate variability is associated with the development of coronary heart disease in individuals with diabetes: the atherosclerosis risk in communities (ARIC) study. Diabetes 51: 3524-3531, 2002.

74. Luhmann M and Hawkley LC. Age differences in loneliness from late adolescence to oldest old age. Dev Psychol 52: 943-959, 2016.

75. Lutgendorf SK, DeGeest K, Dahmoush L, Farley D, Penedo F, Bender D, Goodheart M, Buekers TE, Mendez L, Krueger G, Clevenger L, Lubaroff DM, Sood AK, and Cole SW. Social isolation is associated with elevated tumor norepinephrine in ovarian carcinoma patients. Brain Behav Immun 25: 250-255, 2011.

76. Lutgendorf SK, DeGeest K, Sung CY, Arevalo JM, Penedo F, Lucci J, 3rd, Goodheart M, Lubaroff D, Farley DM, Sood AK, and Cole SW. Depression, social support, and beta-adrenergic transcription control in human ovarian cancer. Brain Behav Immun 23: 176-183, 2009.

77. Marumo T, Schini-Kerth VB, Brandes RP, and Busse R. Glucocorticoids inhibit superoxide anion production and p22 phox mRNA expression in human aortic smooth muscle cells. Hypertension 32: 1083-1088, 1998.

78. Masi CM, Chen HY, Hawkley LC, and Cacioppo JT. A meta-analysis of interventions to reduce loneliness. Pers Soc Psychol Rev 15: 219-266, 2011.

79. McCabe PM, Gonzales JA, Zaias J, Szeto A, Kumar M, Herron AJ, and Schneiderman N. Social environment influences the progression of atherosclerosis in the watanabe heritable hyperlipidemic rabbit. Circulation 105: 354 359, 2002.
80. McKim DB, Patterson JM, Wohleb ES, Jarrett BL, Reader BF, Godbout JP, and Sheridan JF. Sympathetic release of splenic monocytes promotes recurring anxiety following repeated social defeat. Biol Psychiatry 79: 803-813, 2016.

81. McNeal N, Scotti MA, Wardwell J, Chandler DL, Bates SL, Larocca M, Trahanas DM, and Grippo AJ. Disruption of social bonds induces behavioral and physiological dysregulation in male and female prairie voles. Auton Neurosci 180: 9-16, 2014.

82. McPherson M, Smith-Lovin L, and Brashears ME. Social isolation in America: changes in core discussion networks over two decades. Am Sociol Rev 71: 353-375, 2006.

83. Meyer $\mathrm{T}$ and Wirtz PH. Mechanisms of mitochondrial redox signaling in psychosocial stress-responsive systems: new insights into an old story. Antioxid Redox Signal 28: 760-772, 2018.

84. Münzel T, Daiber A, Steven S, Tran LP, Ullmann E, Kossmann S, Schmidt FP, Oelze M, Xia N, Li H, Pinto A, Wild P, Pies K, Schmidt ER, Rapp S, and Kröller-Schön $\mathrm{S}$. Effects of noise on vascular function, oxidative stress, and inflammation: mechanistic insight from studies in mice. Eur Heart J 37: 2838-3849, 2017.

85. Münzel T, Sörensen M, Gori T, Schmidt FP, Rao X, Brook FR, Chen LC, Brook RD, and Rajagopalan S. Environmental stressors and cardio-metabolic disease: part II-mechanistic insights. Eur Heart J 38: 557-564, 2017.

86. Nation DA, Gonzales JA, Mendez AJ, Zaias J, Szeto A, Brooks LG, Paredes J, D’ Angola A, Schneiderman N, and McCabe PM. The effect of social environment on markers of vascular oxidative stress and inflammation in the Watanabe heritable hyperlipidemic rabbit. Psychosom Med 70: 269-275, 2008.

87. Nation DA, Szeto A, Mendez AJ, Brooks LG, Zaias J, Herderick EE, Gonzales J, Noller CM, Schneiderman N, and McCabe PM. Oxytocin attenuates atherosclerosis and adipose tissue inflammation in socially isolated $\mathrm{ApoE}^{-/-}$ mice. Psychosom Med 72: 376-382, 2010.

88. Nelson M and Pinna G. S-norfluoxetine microinfused into the basolateral amygdala increases allopregnanolone levels and reduces aggression in socially isolated mice. Neuropharmacology 60: 1154-1159, 2011.

89. Nikkheslat N, Zunszain PA, Horowitz MA, Barbosa IG, Parker JA, Myint AM, Schwarz MJ, Tylee AT, Carvalho LA, and Pariante CM. Insufficient glucocorticoid signaling and elevated inflammation in coronary heart disease patients with comorbid depression. Brain Behav Immun 48: 8-18, 2015.

90. Nin MS, Martinez LA, Pibiri F, Nelson M, and Pinna G. Neurosteroids reduce social isolation-induced behavioral deficits: a proposed link with neurosteroid-mediated upregulation of BDNF expression. Front Endocrinol (Lausanne) 2: 73, 2011.

91. Norman GJ, Cacioppo JT, Morris JS, Malarkey WB, Berntson GG, and Devries AC. Oxytocin increases autonomic cardiac control: moderation by loneliness. Biol Psychol 86: 174-180, 2011.

92. Ong AD, Uchino BN, and Wethington E. Loneliness and health in older adults: a mini-review and synthesis. Gerontology 62: 443-449, 2016.

93. Ornish D, Scherwitz LW, Doody RS, Kesten D, McLanahan SM, Brown SE, DePuey E, Sonnemaker R, Haynes C, Lester J, McAllister GK, Hall RJ, Burdine JA, and Gotto AM, Jr. Effects of stress management training and 
dietary changes in treating ischemic heart disease. JAMA 249: 54-59, 1983.

94. Pace TW, Hu F, and Miller AH. Cytokine-effects on glucocorticoid receptor function: relevance to glucocorticoid resistance and the pathophysiology and treatment of major depression. Brain Behav Immun 21: 9-19, 2007.

95. Pajovic SB, Pejic S, Stojiljkovic V, Gavrilovic L, Dronjak $\mathrm{S}$, and Kanazir DT. Alterations in hippocampal antioxidant enzyme activities and sympatho-adrenomedullary system of rats in response to different stress models. Physiol Res 55: 453-460, 2006.

96. Paredes J, Szeto A, Levine JE, Zaias J, Gonzales JA, Mendez AJ, Llabre MM, Schneiderman N, and McCabe PM. Social experience influences hypothalamic oxytocin in the WHHL rabbit. Psychoneuroendocrinology 31: 1062-1075, 2006.

97. Peuler JD, Scotti MA, Phelps LE, McNeal N, and Grippo AJ. Chronic social isolation in the prairie vole induces endothelial dysfunction: implications for depression and cardiovascular disease. Physiol Behav 106: 476-484, 2012.

98. Pibiri F, Nelson M, Guidotti A, Costa E, and Pinna G. Decreased corticolimbic allopregnanolone expression during social isolation enhances contextual fear: a model relevant for posttraumatic stress disorder. Proc Natl Acad Sci U S A 105: 5567-5572, 2008.

99. Pinna G. In a mouse model relevant for post-traumatic stress disorder, selective brain steroidogenic stimulants (SBSS) improve behavioral deficits by normalizing allopregnanolone biosynthesis. Behav Pharmacol 21: 438450, 2010.

100. Pinna G and Rasmusson AM. Ganaxolone improves behavioral deficits in a mouse model of post-traumatic stress disorder. Front Cell Neurosci 8: 256, 2014.

101. Powell ND, Sloan EK, Bailey MT, Arevalo JM, Miller GE, Chen E, Kobor MS, Reader BF, Sheridan JF, and Cole SW. Social stress up-regulates inflammatory gene expression in the leukocyte transcriptome via betaadrenergic induction of myelopoiesis. Proc Natl Acad Sci U S A 110: 16574-16579, 2013.

102. Randall G, Bhattacharyya MR, and Steptoe A. Marital status and heart rate variability in patients with suspected coronary artery disease. Ann Behav Med 38: 115-123, 2009.

103. Reddy DS. Physiological role of adrenal deoxycorticosteronederived neuroactive steroids in stress-sensitive conditions. Neuroscience 138: 911-920, 2006.

104. Rico-Uribe LA, Caballero FF, Olaya B, TobiaszAdamczyk B, Koskinen S, Leonardi M, Haro JM, Chatterji S, Ayuso-Mateos JL, and Miret M. Loneliness, social networks, and health: a cross-sectional study in three countries. PLoS One 11: e0145264, 2016.

105. Rodriguez JM, Monsalves-Alvarez M, Henriquez S, Llanos MN, and Troncoso R. Glucocorticoid resistance in chronic diseases. Steroids 115: 182-192, 2016.

106. Scanzano A and Cosentino M. Adrenergic regulation of innate immunity: a review. Front Pharmacol 6: 171, 2015.

107. Schafer SC, Wallerath T, Closs EI, Schmidt C, Schwarz PM, Forstermann U, and Lehr HA. Dexamethasone suppresses eNOS and CAT-1 and induces oxidative stress in mouse resistance arterioles. Am J Physiol Heart Circ Physiol 288: H436-H444, 2005.

108. Schiavone S, Jaquet V, Trabace L, and Krause KH. Severe life stress and oxidative stress in the brain: from animal models to human pathology. Antioxid Redox Signal 18: 1475-1490, 2013.
109. Schiavone S, Sorce S, Dubois-Dauphin M, Jaquet V, Colaianna M, Zotti M, Cuomo V, Trabace L, and Krause KH. Involvement of NOX2 in the development of behavioral and pathologic alterations in isolated rats. Biol Psychiatry 66: 384-392, 2009.

110. Schraml E, Quan P, Stelzer I, Fuchs R, Skalicky M, Viidik A, and Schauenstein K. Norepinephrine treatment and aging lead to systemic and intracellular oxidative stress in rats. Exp Gerontol 42: 1072-1078, 2007.

111. Servier Medical Art. Powerpoint image bank Servier. www.servier.at/content/powerpoint-image-bank (last accessed October 15, 2017).

112. Shaffer F, McCraty R, and Zerr CL. A healthy heart is not a metronome: an integrative review of the heart's anatomy and heart rate variability. Front Psychol 5: 1040, 2014.

113. Shankar A, McMunn A, Banks J, and Steptoe A. Loneliness, social isolation, and behavioral and biological health indicators in older adults. Health Psychol 30: 377-385, 2011.

114. Shao Y, Yan G, Xuan Y, Peng H, Huang QJ, Wu R, and $\mathrm{Xu} \mathrm{H}$. Chronic social isolation decreases glutamate and glutamine levels and induces oxidative stress in the rat hippocampus. Behav Brain Res 282: 201-208, 2015.

115. Shively CA, Clarkson TB, and Kaplan JR. Social deprivation and coronary artery atherosclerosis in female cynomolgus monkeys. Atherosclerosis 77: 69-76, 1989.

116. Siegrist $J$ and Sies H. Disturbed redox homeostasis in oxidative distress: a molecular link from chronic psychosocial work stress to coronary heart disease? Circ Res 121: 103-105, 2017.

117. Silverman MN and Sternberg EM. Glucocorticoid regulation of inflammation and its functional correlates: from HPA axis to glucocorticoid receptor dysfunction. Ann NY Acad Sci 1261: 55-63, 2012.

118. Siuda D, Tobias S, Rus A, Xia N, Forstermann U, and Li H. Dexamethasone upregulates Nox1 expression in vascular smooth muscle cells. Pharmacology 94: 13-20, 2014.

119. Siuda D, Wu Z, Chen Y, Guo L, Linke M, Zechner U, Xia N, Reifenberg G, Kleinert H, Forstermann U, and Li H. Social isolation-induced epigenetic changes in midbrain of adult mice. J Physiol Pharmacol 65: 247-255, 2014.

120. Sloan EK, Capitanio JP, and Cole SW. Stress-induced remodeling of lymphoid innervation. Brain Behav Immun 22: 15-21, 2008.

121. Sloan EK, Capitanio JP, Tarara RP, and Cole SW. Social temperament and lymph node innervation. Brain Behav Immun 22: 717-726, 2008.

122. Sloan EK, Capitanio JP, Tarara RP, Mendoza SP, Mason WA, and Cole SW. Social stress enhances sympathetic innervation of primate lymph nodes: mechanisms and implications for viral pathogenesis. J Neurosci 27: 88578865, 2007.

123. Smith TW, Cribbet MR, Nealey-Moore JB, Uchino BN, Williams PG, Mackenzie J, and Thayer JF. Matters of the variable heart: respiratory sinus arrhythmia response to marital interaction and associations with marital quality. $J$ Pers Soc Psychol 100: 103-119, 2011.

124. Steptoe A and Kivimaki M. Stress and cardiovascular disease: an update on current knowledge. Annu Rev Public Health 34: 337-354, 2013.

125. Steptoe A, Shankar A, Demakakos P, and Wardle J. Social isolation, loneliness, and all-cause mortality in older men and women. Proc Natl Acad Sci U S A 110: 5797-5801, 2013.

126. Sun P, Smith AS, Lei K, Liu Y, and Wang Z. Breaking bonds in male prairie vole: long-term effects on emotional 
and social behavior, physiology, and neurochemistry. Behav Brain Res 265: 22-31, 2014.

127. Sunderkotter C, Nikolic T, Dillon MJ, Van Rooijen N, Stehling M, Drevets DA, and Leenen PJ. Subpopulations of mouse blood monocytes differ in maturation stage and inflammatory response. J Immunol 172: 4410-4417, 2004.

128. Swirski FK, Nahrendorf M, Etzrodt M, Wildgruber M, Cortez-Retamozo V, Panizzi P, Figueiredo JL, Kohler RH, Chudnovskiy A, Waterman P, Aikawa E, Mempel TR, Libby P, Weissleder R, and Pittet MJ. Identification of splenic reservoir monocytes and their deployment to inflammatory sites. Science 325: 612-616, 2009.

129. Szeto A, Nation DA, Mendez AJ, Dominguez-Bendala J, Brooks LG, Schneiderman N, and McCabe PM. Oxytocin attenuates NADPH-dependent superoxide activity and IL6 secretion in macrophages and vascular cells. Am J Physiol Endocrinol Metab 295: E1495-E1501, 2008.

130. Szeto A, Rossetti MA, Mendez AJ, Noller CM, Herderick EE, Gonzales JA, Schneiderman N, and McCabe PM. Oxytocin administration attenuates atherosclerosis and inflammation in Watanabe Heritable Hyperlipidemic rabbits. Psychoneuroendocrinology 38: 685-693, 2013.

131. Tan KS, Nackley AG, Satterfield K, Maixner W, Diatchenko L, and Flood PM. Beta2 adrenergic receptor activation stimulates pro-inflammatory cytokine production in macrophages via PKA- and NF-kappaB-independent mechanisms. Cell Signal 19: 251-260, 2007.

132. Thayer JF and Lane RD. The role of vagal function in the risk for cardiovascular disease and mortality. Biol Psychol 74: 224-242, 2007.

133. Thayer JF and Sternberg E. Beyond heart rate variability: vagal regulation of allostatic systems. Ann N Y Acad Sci 1088: 361-372, 2006.

134. Thayer JF, Yamamoto SS, and Brosschot JF. The relationship of autonomic imbalance, heart rate variability and cardiovascular disease risk factors. Int J Cardiol 141: 122-131, 2010.

135. Theeke LA. Predictors of loneliness in U.S. adults over age sixty-five. Arch Psychiatr Nurs 23: 387-396, 2009.

136. Tobias S, Habermeier A, Siuda D, Reifenberg G, Xia N, Closs EI, Forstermann U, and Li H. Dexamethasone, tetrahydrobiopterin and uncoupling of endothelial nitric oxide synthase. J Geriatr Cardiol 12: 528-539, 2015.

137. Tsuji H, Larson MG, Venditti FJ, Jr., Manders ES, Evans JC, Feldman CL, and Levy D. Impact of reduced heart rate variability on risk for cardiac events. The Framingham Heart Study. Circulation 94: 2850-2855, 1996.

138. Valtorta NK, Kanaan M, Gilbody S, Ronzi S, and Hanratty $\mathrm{B}$. Loneliness and social isolation as risk factors for coronary heart disease and stroke: systematic review and meta-analysis of longitudinal observational studies. Heart 102: 1009-1016, 2016.

139. Vandevyver S, Dejager L, Tuckermann J, and Libert C. New insights into the anti-inflammatory mechanisms of glucocorticoids: an emerging role for glucocorticoid-receptor-mediated transactivation. Endocrinology 154: 993-1007, 2013.

140. Waller C, Bauersachs J, Hoppmann U, Hoch J, Krause S, Szabo F, Engler H, Rottler E, Herrmann-Lingen C, and Gundel H. Blunted cortisol stress response and depressioninduced hypocortisolism is related to inflammation in patients with CAD. J Am Coll Cardiol 67: 1124-1126, 2016.

141. Wallerath T, Godecke A, Molojavyi A, Li H, Schrader J, and Forstermann U. Dexamethasone lacks effect on blood pressure in mice with a disrupted endothelial NO synthase gene. Nitric Oxide 10: 36-41, 2004.

142. Wallerath T, Witte K, Schafer SC, Schwarz PM, Prellwitz W, Wohlfart P, Kleinert H, Lehr HA, Lemmer B, and Forstermann U. Down-regulation of the expression of endothelial NO synthase is likely to contribute to glucocorticoid-mediated hypertension. Proc Natl Acad Sci U S A 96: 13357-13362, 1999.

143. Weber MD, Godbout JP, and Sheridan JF. Repeated social defeat, neuroinflammation, and behavior: monocytes carry the signal. Neuropsychopharmacology 42: 46-61, 2017.

144. Wenzel P, Knorr M, Kossmann S, Stratmann J, Hausding M, Schuhmacher S, Karbach SH, Schwenk M, Yogev N, Schulz E, Oelze M, Grabbe S, Jonuleit H, Becker C, Daiber A, Waisman A, and Münzel T. Lysozyme Mpositive monocytes mediate angiotensin II-induced arterial hypertension and vascular dysfunction. Circulation 124: 1370-1381, 2011.

145. Wenzel P, Kossmann S, Münzel T, and Daiber A. Redox regulation of cardiovascular inflammationimmunomodulatory function of mitochondrial and Noxderived reactive oxygen and nitrogen species. Free Radic Biol Med 109: 48-60, 2017.

146. Williams RB, Barefoot JC, Califf RM, Haney TL, Saunders WB, Pryor DB, Hlatky MA, Siegler IC, and Mark DB. Prognostic importance of social and economic resources among medically treated patients with angiographically documented coronary artery disease. JAMA 267: 520-524, 1992.

147. Wohleb ES, McKim DB, Shea DT, Powell ND, Tarr AJ, Sheridan JF, and Godbout JP. Re-establishment of anxiety in stress-sensitized mice is caused by monocyte trafficking from the spleen to the brain. Biol Psychiatry 75: 970-981, 2014.

148. Yang KM and Victor C. Age and loneliness in 25 European nations. Ageing Soc 31: 1368-1388, 2011.

149. Yang KM and Victor CR. The prevalence of and risk factors for loneliness among older people in China. Ageing Soc 28: 305-327, 2008.

150. Yang $S$ and Zhang L. Glucocorticoids and vascular reactivity. Curr Vasc Pharmacol 2: 1-12, 2004.

151. You JM, Yun SJ, Nam KN, Kang C, Won R, and Lee EH. Mechanism of glucocorticoid-induced oxidative stress in rat hippocampal slice cultures. Can J Physiol Pharmacol 87: 440-447, 2009.

152. Zlatkovic J, Todorovic N, Boskovic M, Pajovic SB, Demajo M, and Filipovic D. Different susceptibility of prefrontal cortex and hippocampus to oxidative stress following chronic social isolation stress. Mol Cell Biochem 393: 43-57, 2014.

Address correspondence to:
Prof. Huige Li
Department of Pharmacology
Johannes Gutenberg University Medical Center
Obere Zahlbacher Strasse 67
Mainz.55131
Germany
E-mail: huigeli@uni-mainz.de

Date of first submission to ARS Central, August 4, 2017; date of final revised submission, August 4, 2017; date of acceptance, August 13, 2017. 


\section{Abbreviations Used}

ALLO $=$ allopregnanolone

$\mathrm{CHD}=$ coronary heart disease

CTRA $=$ conserved transcriptional response to adversity

$\mathrm{CVD}=$ cardiovascular disease

eNOS $=$ endothelial nitric oxide synthase

GABA $=\gamma$-aminobutyric acid

$\mathrm{GR}=$ glucocorticoid receptor

HF-HRV = high-frequency heart rate variability

HPA = hypothalamic-pituitary-adrenal

$\mathrm{HRV}=$ heart rate variability
$\mathrm{NO}=$ nitric oxide

$\mathrm{NOX}=\mathrm{NADPH}$ oxidase

PBMC $=$ peripheral blood mononuclear cell

PSI $=$ perceived social isolation

ROS $=$ reactive oxygen species

$\mathrm{RSD}=$ repeated social defeat

$\mathrm{SBP}=$ systolic blood pressure

SDR $=$ social disruption stress

SIV $=$ simian immunodeficiency virus

SNS $=$ sympathetic nervous system

$\mathrm{TPR}=$ total peripheral resistance 